\title{
A RETÓRICA DA SUPERIORIDADE E SUA RELAÇÃO COM AS PROPOSTAS DE JACQUES DUPUIS PARA O DIÁLOGO INTER-RELIGIOSO PELO VIÉS PNEUMATOLÓGICO*
}

\author{
Fabrício Veliq ${ }^{* *}$ \\ Karen de Souza Colares***
}

\section{RESUMO}

O presente artigo tem o intuito de estabelecer a relação existente entre a retórica da superioridade presente no cristianismo ao longo de sua história e as propostas de Jacques Dupuis para o diálogo inter-religioso pelo viés pneumatológico. Iniciamos com um pequeno percurso histórico, mostrando como que a retórica da superioridade se desenvolveu ao longo da história do povo de Israel e, posteriormente na teologia cristã até os dias atuais. Em um segundo momento, abordamos as propostas de Jacques Dupuis para o diálogo inter-religioso em seu viés pneumatológico, o qual traz o cristianismo como responsável pela interpretação correta das diversas experiências religiosas presentes nas outras religiões. Concluímos ressaltando a importância do desenvolvimento de novas teologias que abandonem tal perspectiva da superioridade.

Palavras-chave: Jacques Dupuis; retórica; relação; superioridade

* O presente artigo foi financiado pela Coordenação de Aperfeiçoamento de Pessoal de Nível Superior (CAPES).

** Doutor em Teologia pela Faculdade Jesuíta de Filosofia e Teologia de Belo Horizonte (FAJE). Doutor em Teologia pela Katholieke Universiteit Leuven (KU Leuven). Membro do grupo de pesquisa Teologia e Diversidade afetivo-sexual na Faculdade Jesuíta de Filosofia e Teologia de Belo Horizonte (FAJE).

*** Mestra e Doutoranda em Teologia pela Faculdade Jesuíta de Filosofia e Teologia de Belo Horizonte (FAJE). Membro do grupo de pesquisa Teologia e Diversidade afetivo-sexual na Faculdade Jesuíta de Filosofia e Teologia de Belo Horizonte (FAJE). 
THE RHETORICAL OF SUPERIORITY AND ITS RELATION WITH JACQUES DUPUIS' PROPOSALS ON PNEUMATOLOGICAL INTER-RELIGIOUS DIALOGUE

\section{ABSTRACT}

This article aims to establish the relation between the rhetorical of superiority on the history of christianity and Jacques Dupuis' proposals on pneumatological inter-religious dialogue. To do so, we have begun with an historical overview, showing how the rhetorical of superiority has been developed in Israel's history and, posteriorly, in the christian theology until nowadays. After, we have approached Jacques Dupuis' proposals on pneumatological inter-religious dialogue, in which he points out christianity as responsible to provide the correct interpretations about other religious experiences developed by other religions. We have concluded by pointing out the importance of development of new theologies that can exclude this perspective of superiority.

Keywords: Jacques Dupuis; rhetoric; relation; superiority

\section{LA RETORIA DE LA SUPERIORIDAD Y SU RELACIÓN CON LAS PROPUESTAS DE JACQUES DUPUIS PARA EL DIÁLOGO INTER-RELIGIOSO POR EL VIEO PNEUMATOLÓGICO}

\section{RESUMEN}

El presente artículo tiene el propósito de establecer la relación existente entre la retórica de la superioridad presente en el cristianismo a lo largo de su historia y las propuestas de Jacques Dupuis para el diálogo interreligioso por el sesgo pneumatológico. Iniciamos con un pequeño recorrido histórico, mostrando cómo la retórica de la superioridad se desarrolló a lo largo de la historia del pueblo de Israel y, posteriormente en la teología cristiana hasta los días actuales. En un segundo momento, abordamos las propuestas de Jacques Dupuis para el diálogo interreligioso en su sesgo pneumatológico, en el que trae el cristianismo como responsable de la correcta interpretación de las diversas experiencias religiosas presentes en las otras religiones. Concluimos resaltando la importancia del desarrollo de nuevas teologías que abandonen esa perspectiva de la superioridad.

Palabras clave: Jacques Dupuis; la retórica; relación; superioridad. 


\section{INTRODUÇÃO}

"Um homem livre é como a sombra de um deus;
um escravo é como a sombra de um homem livre;
mas o rei, ele é semelhante à imagem de Deus"
(Jean-Louis SKA, 2016, p. 63)

Ao enviar uma carta ao Rei da Assíria, Asaradon, o autor deste texto mesopotâmico do século VII a. C não apenas registra um modo de pensar típico do mundo antigo, mas deixa entrever uma constante tendência humana: organizar de modo hierárquico a diversidade que compõe o grupo humano.

Categorias diversificadas são utilizadas para tal escalonamento. Hora, tem-se a pertença étnica como elemento capaz de dizer quais pessoas são superiores e quais inferiores, hora a posição socioeconômica será a linha divisória entre topo e base da pirâmide social, e se estes pudessem soar insuficientes para a segregação humana pretendida, o gênero apareceria como poderoso instrumento na tarefa de classificação antropológica.

Ao contrário do que possa parecer à primeira vista, estas categorias em geral são articuladas de maneira simultânea, dando origem a um intrincado sistema de opressão humana, no qual as várias pertenças de um/a indivíduo/a contribuem para a posição que ocupará no jogo das relações sociais.

No horizonte de tão complexa estruturação, evidentemente outros dados atenuarão ou engessarão com ainda mais força tais delimitações, como por exemplo, a religião. A abertura à transcendência é um dado amplamente reconhecido no seio de diversos campos científicos. As análises das Ciências das Religiões têm demonstrado que pensar o ser humano é pensar um ente que recorre a realidades que estão para além de si mesmo como fundamentação de seu ser e existência - curiosamente, a noção de criaturalidade, ou seja, de existir por disposição alheia, é um traço a marcar narrativas e mitos da criação de culturas diversas.

Assim, a retórica religiosa será fator cooptado para reiterar o estado de coisas ou para promover rupturas que levem semelhante escalonamento à bancarrota. Considerando-se o contexto mais amplo das sociedades 
ocidentais, a pertença religiosa que emerge para urgente análise, dado seu predominante papel na formação destas, é a tradição judaico-cristã ou mais comumente, o Cristianismo. Analisaremos, assim, a partir dessa retórica da superioridade, as propostas do teólogo belga Jacques Dupuis para o diálogo inter-religioso por meio da pneumatologia cristã, tentando mostrar que sua abordagem se insere dentro da dinâmica de ver o cristianismo como superior às outras religiões com as quais dialoga.

Aqui, é importante salientar que a escolha de recorte não se deve ironicamente à pressuposição de superioridade religiosa, mas ao reconhecimento de que o imaginário antropológico ocidental tem raízes nesta tradição de fé.

\section{O CRISTIANISMO E A RETÓRICA DA SUPERIORIDADE}

Não é possível falar da fé cristã sem compreensão do pano de fundo cultural e religioso que compõe seu nascedouro. A figura de Jesus de Nazaré só pode fazer sentido à luz de um complexo conjunto de expectativas que foram embaladas pelo antigo Israel ao longo de sua história. Por isso, se faz necessário retroceder alguns séculos para se averiguar as fontes das quais brotam a tradição religiosa que agora temos diante de nós.

A natureza da relação de Israel com seu Deus, definida em termos de eleição, foi um elemento muitas vezes mal compreendido. Encarada em alguns momentos como um privilégio merecido, algo a destacar-lhes dos povos ao derredor, a eleição assumiu contornos que excederam a definição de uma identidade sendo interpretada como um indicativo de sua pretensa superioridade. A pertença étnica e religiosa se amalgamou dando origem a sentimentos e práticas exclusivistas'. Múltiplos textos bíblicos apresentam correções dirigidas ao povo eleito de que a escolha divina não se baseava na grandeza do povo $^{2}$, mas tinha a graciosidade

\footnotetext{
A experiência do Antigo Israel em relação ao estrangeiro assumiu novos contornos a partir da experiência do exílio babilônico. O Livro de Esdras demonstrará de maneira clara, o quanto estavam dispostos a medidas deveras radicais para a manutenção da pureza étnica. Esdras orienta que as mulheres estrangeiras casadas com israelitas fossem despedidas de volta a suas terras, diluindo laços matrimoniais de longa data.

2 Ver desenvolvimento proposto por HARRIS, R.Laird; ARCHER JR, Gleason L.; WALTKE, Bruce K. Dicionário Internacional de Teologia do Antigo Testamento. São Paulo: Vida Nova, 1998 (Aqui p. 167).
} 
divina como seu leito. Preservar a pureza e unidade do povo foi uma batalha presente de modo perene em sua história. Em tentativas por vezes violentas de conservá-las, o discurso religioso se viu cooptado por intenções etnocêntricas, que serviram ao intuito de eliminação e subjugação dos povos ao redor bem como de sua proteção, dado o fato de que, a despeito do discurso acerca de sua eleição tomado em termos de preeminência, Israel sempre foi inexpressivo em termos bélicos e políticos.

Não apenas a preeminência em termos religiosos e étnicos perpassou a experiência de fé daqueles vinculados à fé judaica. Discursos de superioridade pertencentes ao contexto histórico-cultural da época compõem o pano de fundo no qual nasce e se desenvolve sua fé. Entre estes enunciados, chama a atenção, por seu volume e relevância em debates hodiernos, aqueles referentes ao gênero.

Como sociedade tribal, a organização socioeconômica do Antigo Israel privilegiava, sob vários aspectos, a figura do masculino. Isso, evidentemente não implica dizer que mulheres não possuíam papéis sociais a serem desempenhados ou que estes não tivessem importância no quadro geral da ordenação, mas tão somente que a referência primária ao redor da qual se organizavam as prioridades era o masculino. A descendência patrilinear agregada ao rito da circuncisão - símbolo de pertença ao povo eleito - permitiu aos homens israelitas gozarem de posição privilegiada no conjunto de sua vivência étnica e religiosa. Neste último, tal predominância se faz notar na linguagem utilizada para expressar as experiências de fé do Antigo Israel, linguagem, sobretudo, androcêntrica - afirmação que pode ser confirmada pela quantidade de metáforas masculinas para se abordar a figura divina, funcionando as imagens femininas como exceção ou o outro do masculino.

A disparidade entre os sexos nunca foi exclusividade do mundo judaico. Hierarquizações diversas concretizadas na cultura greco-romana são descritas sob o mote Paulino, tais como homem/mulher, grego/ judeu e escravo/livre, bem conhecidas dos leitores bíblicos. Dissimetria conhecida e atestada na Antiguidade grega, a questão do gênero estava ligada de maneira estreita às dimensões do público e privado. Novamente, cabe o esclarecimento de que as mulheres não estavam totalmente 
banidas da dimensão pública e nem a esfera doméstica era destituída de relevância política, (EkkehardSTEGEMANN, WolfgangSTEGEMANN, 2004, p. 406) mas que, em termos de oportunidades, as mulheres possuíam menos acesso a recursos políticos, econômicos e sociais da vida pública. A divisão de papéis, espaço geográfico e atribuição de características específicas era claramente regida pela categoria de gênero com claro demérito da figura feminina. A reação masculina quando da inserção de mulheres em assuntos políticos pode ser averiguada na citação de Catão, O Antigo, em Lívio:

Eu, contudo, tive de passar há pouco, não sem um certo rubor nas faces, por uma fila de mulheres para vir ao Fórum [...] Que costume é esse de ir a público, sitiar as ruas e dirigir a palavra a homens desconhecidos? [...] Os nossos antepassados não queriam que as mulheres resolvessem qualquer assunto, nem mesmo um privado, sem um avalista e tutor; elas deveriam estar sob o poder de seus pais, irmãos ou marido; nós, porém, inclusive já toleramos, sendo do agrado dos deuses, que elas assumam diligentemente assuntos de Estado e interfiram no Fórum, em reuniões e assembleias populares, convocadas e públicas. (Ekkehard STEGEMANN, Wolfgang STEGEMANN, 2004, p. 408).

O período intertestamentário viu o surgimento de um fenômeno ainda inaudito: a misoginia. Em discussões cada vez mais elaboradas sobre o surgimento do mal, a mulher foi identificada como responsável pela entrada do pecado no mundo ${ }^{3}$ - estigma diante do qual se rebela apenas para confirmar sua suposta má índole.

A proeminência social e religiosa dos varões era ponto já estabelecido na época do movimento de Jesus. Envolvido em várias cenas polêmicas, Jesus demonstra não se orientar por tal diretriz, mas trata ambos os sexos como seres humanos integrais, convidando-os à graça e responsabilizando-os por suas decisões. Potencialmente subversivo e igualitário, o movimento, entretanto, aparenta experimentar, em anos seguintes, certa patriarcalização. Já na escrita das cartas pastorais, os autores parecem esquecer que nenhuma outra pertença deveria ser refe-

Eclesiástico 25,13-26. 
rencia de seu valor ou identidade(Cf. Marga STROHER, 2004, p. 105-136).

$\mathrm{Na}$ Idade Patrística, Agostinho, um dos mais expressivos teólogos da Igreja cristã Ocidental sugere um modelo de dualismo antropológico que tornou a situação feminina ainda mais degradante. Pressupondo hierarquia não apenas entre seres humanos, mas entre as partes integrantes de cada ser humano, sua antropologia conduziu paulatinamente a que os sexos fossem relacionados a tais partes, cabendo ao feminino a representação da parte humana carnal. Semelhante associação é parte integrante de uma longa história de tratamento da mulher como parte moralmente mais vulnerável, de pouca disciplina e razão. Outros autores do período também trabalharam a imagem feminina, circunscrevendo-a a tarefas de menor importância, aquelas tidas como carnais (Andrew LOUTH, 2001). A maneira como os pais interpretavam os textos escriturísticos também contribuiu em grande medida para que se naturalizasse uma determinada estereotipia concernente às mulheres. A intertextualidade, prática de se interpretar um texto à luz de outro removido de seu respectivo contexto, cria um argumento novo que soa aparentemente natural, dado que seus respectivos distintivos contextuais estão sendo omitidos na articulação. Assim, ideologias específicas são corroboradas por textos bíblicos deslocados de seu ambiente original.

O enaltecimento da vida celibatária durante a Idade Média se nutriu da suspeita em relação ao feminino como fonte de tentação. As palavras de Marbode, bispo de Rennes e depois monge de Angers no século XI o confirmam de modo contundente:

Dentre as incontáveis armadilhas que nosso inimigo ardiloso armou através de todas as colinas e planícies do mundo, a pior e aquela que quase ninguém pode evitar é a mulher, cepa de desgraça, muda de todos os vícios, que engendrou no mundo inteiro os mais numerosos escândalos [...] A mulher, doce mal, ao mesmo tempo favo de cera e veneno, que com um gládio untado de mel corta o coração até dos sábios (MARBODE ApudJean DELUMEAU, 1989, p.318).

O advento da imprensa, hoje reverenciado como ícone do progresso humano, não escapou incólume à retórica da superioridade. Jean Delumeau relata em uma de suas obras a presença de coletâneas de folhetins 
promotores da misoginia na França à época da Renascença. Segundo o historiador, 7 em cada 10 provérbios franceses dos séculos XV-XVII são adversos à figura feminina. Se valendo de artifícios burlescos as plateias foram divertidas com a noção de algo como uma subcategoria humana.

"Coração de mulher engana o mundo, pois nele tudo é malícia".

"Mulher é mãe de todo dano. Dela vem todo mal e engano".

"Mulher sabe arte antes do Diabo".

"Luto de mulher morta dura até a porta".

"A quem Deus quer ajudar, morre-lhe a mulher" (Jean DELUMEAU, 1989, p. 342).

A Idade Média foi muitas vezes referida de maneira jocosa pela expressão Idade das Trevas. O que se deseja, ao se recorrer a tal uso, é ressaltar a sensível diferença em termos da racionalidade e esclarecimento abarcados pelo período lluminista e cujas benesses estiveram ausentes no período anterior. A despeito de todos os avanços técnicos e científicos que receberam boas-vindas a partir dos ideais deste período de luzes, as hierarquias humanas não serão uma dentre suas conquistas. No curso histórico, a temática da superioridade emergirá repetidamente sob novas roupagens e velhos preconceitos.

Exemplos de injustas hierarquias antropológicas poderiam ser fornecidos até à exaustão, mas estes pequenos excertos já se fazem suficientes para algumas reflexões.

A primeira evidência que vem à baila quando se toma o tema da retórica da superioridade é o fato de que não há nada novo em usar deste artifício para a afirmação seja de uma etnia, gênero, classe social ou pertença religiosa. Nos primórdios da história humana já se pode atentar à sempre reiterada tentativa de dizer quais devem exercer poder e quais devem a ele se submeter ${ }^{4}$. Outro elemento desta discussão ao qual se deve dar significativa atenção é o uso que se pode fazer da religião para manter o status quo. Embora os textos de referência

4 Os relatos da criação registrados em Gênesis 1 e 2-3 tratam a relação entre os sexos com sensível diferença. Se no capítulo 1 a igualdade e dignidade de ambos estão baseadas na imagem e semelhança com Deus, já o relato seguinte constata as relações sociais vigentes em termos de domínio e submissão no bojo desta relação. 
do Cristianismo se apresentem como fonte de libertação diante de estruturas injustas, puderam reiteradas vezes ser utilizados com outros intuitos. Isso aponta ao fato de que um texto nunca é acessado de maneira direta, mas sempre mediado por uma hermenêutica que pode fazer jus a seu contexto e ímpeto primário.

Se certa noção de superioridade atravessou de múltiplas maneiras a experiência judaico-cristã, a pergunta que surge em cena é pelo relacionamento atual do Cristianismo com outras religiões. Existe algo como uma retórica de proeminência a impedir o diálogo com tradições religiosas diversas? Podem-se fazer apontamentos rumo à correção desta situação de modo que a pertença religiosa não seja referida como característica a elevar um ser humano acima de outro?

\section{UMA PROPOSTA DE JACQUES DUPUIS}

Diante do contexto trazido na primeira parte do artigo, analisaremos um exemplo no qual pode ser percebida certa visão de superioridade do Cristianismo frente às outras religiões. Para tal, abordaremos a proposta de diálogo inter-religioso pelo viés da pneumatologia desenvolvida por Jacques Dupuis.

Jacques Dupuis, teólogo jesuíta, nascido na Bélgica em 1923 e falecido em 2004, é grandemente conhecido por seu trabalho teológico acerca do diálogo inter-religioso, principalmente pelo viés cristológico. Contudo, Dupuis também tenta propor a questão do diálogo inter-religioso pelo viés pneumatológico. Essa virada à pneumatologia, como nos mostra Yong, pode ser percebida no livro Jesus Christ and His Spirit, Nessa obra, tem a consciência de que a reflexão teológica, se quiser ser plausível, deve se basear na experiência de vida e se agarrar a isso em cada passo, devendo também ser exposta e testada pelas realidades do mundo moderno (cf. Jacques DUPUIS, 1976, p. 181-218)5.

Dupuis está consciente dos esforços feitos em uma tentativa de avaliação do mundo religioso por meio de um método indutivo e que esses esforços se concentraram em uma teologia da "presença escondida de Cristo" (Jacques DUPUIS, 1976, p. 183). Porém, para Dupuis,

Chamamos a atenção para o nome do autor que se encontra errado na própria publicação, constando como James Dupuis. 
aparentemente, se abre uma nova via que é baseada na experiência dos não cristãos com Deus e que consiste em descobrir na vida religiosa dos não cristãos a presença e influência do Espírito Santo que não está limitada à Igreja.

Para Dupuis,

essa abordagem é fundada na crença cristã de que o mundo no qual todo homem vive sua vida é o mundo já redimido por causa do mistério histórico de Cristo que culminado no Pentecostes, trouxe uma nova criação. A efusão escatológica do Espírito que é resultado da glorificação de Cristo não é limitada às fronteiras da Igreja cristã; ela se estende a todo o universo. O Espírito Santo está atualmente animando o cosmos inteiro e transformando todas as coisas (Jacques DUPUIS, 1976, p. 183).

Essa virada na abordagem de Jacques Dupuis, no entanto, não é desvencilhada da presença oculta de Cristo da qual falamos acima. Dupuis vê como parcialmente distinta, mas não separada, uma vez que o Espírito é ligado ao Senhor ressuscitado e, dessa forma, cristologia e pneumatologia são inseparáveis. Para Dupuis, é a influência do Espírito que manifesta a presença de Cristo e não o contrário. Se isso é verdade, então, para nosso teólogo, a abordagem pneumatológica se torna vantajosa ao lidar com as experiências religiosas dos não cristãos.

Algo que parece ser interessante ressaltar nessa abordagem de Dupuis é que ele ainda se encontra preocupado com a questão da salvação, mais do que com a questão do diálogo inter-religioso, uma vez que "o teólogo não pode se satisfazer com repetir de maneira abstrata a tradicional afirmação que é possível para ao homem ser salvo fora da cristandade; ele deve procurar descobrir a realidade da salvação na vida dos não cristãos" (Jacques DUPUIS, 1976, p. 184).Sua preocupação é perceber como a ação do Espírito é mediada naqueles que vivem comprometidos com a fé em sua tradição religiosa. Para isso, retoma o tema biblicamente, mostrando como a ação do Espírito se dá no Antigo e Novo Testamento.

Com o evento narrado em Atos 10, em que Pedro, enquanto falava, vê descer o Espírito sobre aqueles que ainda não tinham terminado de ouvir o evangelho e também nos escritos de Paulo a respeito da presen- 
ça do Espírito e do Cristo enquanto evento cósmico, Dupuis defende a tese de que o Espírito pode operar mesmo naqueles que não receberam o Evangelho. No entanto, ainda permanece na linha tradicional católica, de que a Igreja é a esfera privilegiada da influência do Espírito, mesmo que essa influência se estenda para fora de suas fronteiras.

A Igreja e o cosmos representam, por assim dizer, círculos concêntricos em volta do centro Cristo de quem a ação universal alcança a ambos; a Igreja é a zona interna e a esfera imediata da influência de Cristo pelo seu Espírito, o cosmos é o círculo de fora (Jacques DUPUIS, 1976, p. 190).

Com isso, justifica que da mesma forma que o Espírito é a alma da Igreja, Ele é também a alma do mundo.

Para Dupuis, nos textos do Vaticano II acerca do diálogo inter-religioso, há certa evolução de pensamento, passando de uma consideração abstrata a respeito da possível salvação para um "concreto e alegre reconhecimento da ação efetiva da presença da graça de Deus" ${ }^{6}$ (Jacques DUPUIS, 1976, p. 198).

Essa presença da graça é atribuída ao trabalho do Espírito Santo. “O Espírito está operante atualmente nos não cristãos; sua influência os alcança, misteriosamente e secretamente, na situação concreta em que vivem sua vida religiosa" (Jacques DUPUIS, 1976, p. 198).

Dentre os documentos da Igreja Católica acerca do diálogo inter-religioso entre cristãos e não cristãos, Dupuis considera que na constituição pastoral Gaudium et Spes se encontra a carta magna para o esse propósito7. Com isso em mente, defende que:

6 Aqui se torna importante assinalar que, conforme nos aponta Dupuis, são quatro documentos no Vaticano II que abordam o tema das religiões mundiais: a constituição dogmática Lumen Gentium, a declaração Nostra Aetete, o Decreto Ad Gentes e a constituição pastoral Gaudium et Spes.

7 Para ele, essa "carta magna" se encontra em Gaudium et Spes, 93,1: “Ora, a vontade do Pai é que reconheçamos e amemos efetivamente em todos os homens a Cristo, por palavra e por obras, dando assim testemunho da verdade e comunicando aos outros o mistério do amor do Pai celeste. Deste modo, em toda a terra, os homens serão estimulados à esperança viva, dom do Espírito Santo, para que finalmente sejam recebidos na paz e felicidade infinitas, na pátria que refulge com a glória do Senhor". 
Dialogo inter-religioso deve ser baseado no reconhecimento da presença ativa do Espírito Santo em outros; isso consiste no discernimento comum dos sussurros do Espírito experimentado por todos; tende a uma ação comum direcionada a construir na terra, em esperança e através do Espírito, uma irmandade universal de homens em Deus, que anuncia, mesmo que imperfeitamente, a realização da família de Deus no Reino celestial (Jacques DUPUIS, 1976, p. 202).

Para Dupuis, o ponto de partida para o diálogo inter-religioso precisa ser a comunhão espiritual que surge de uma experiência de Deus compartilhada, uma vez que cada experiência com Deus é conhecida como uma colheita do Espírito na pessoa, mesmo que aquele que experimenta a presença de Deus não saiba que é o Espírito.

O trabalho do/a cristão/ã nesse diálogo é, então, reconhecer a ação do Espírito naquele/a com quem dialoga, em uma tarefa profética de interpretar o evento da salvação encontrado no/a outro/a para, em tempo oportuno, declarar a esse/a outro/a a fonte da salvação com o anúncio do evangelho (cf. Jacques DUPUIS, 1976, p. 203-204).

Juntamente com isso, Dupuis propõe um segundo ponto de abordagem para o diálogo entre cristãos/ãs e não cristãos/ãs. Esse outro ponto diz respeito aos/às que aderem às outras religiões e à experiência do Espírito que é feita por essas pessoas. Para ele, o/a teólogo/a cristão/ã deve constantemente tentar ir além das ideias que os/as não cristãos/ ãs fazem a respeito de Deus e dos conceitos que usam para falar do mistério divino, para que possam comungar, juntamente com aqueles/ as que não são cristãos/ãs, da experiência que fazem de Deus, uma vez que, do ponto de vista existencial, afirma Dupuis, "toda experiência, se ela é genuína e verdadeira, é uma experiência do Espírito, por mais inadequadamente identificada e imperfeitamente expressa" (Jacques DUPUIS, 1976, p. 205).

\section{A QUESTÃO DAS ESCRITURAS}

Outro tema abordado por Dupuis é a pergunta a respeito das escrituras, ritos e práticas religiosas das religiões não cristãs. Sua pergunta é sobre o como elas podem transmitir a influência universal do Espírito aos/às não cristãos/ãs e como tais experiências sustentam neles/as uma 
experiência pessoal de Deus (cf.Jacques DUPUIS, 1976, p. 206). No entanto, nosso teólogo não consegue responder essa questão, uma vez que, em sua forma de ver:

Seu significado verdadeiro como possível canal de salvação para não cristãos não pode ser decidido por uma evolução teológica de seu conteúdo; isso só pode ser suposto pelo impacto que eles fazem em suas vidas religiosas, onde quer que essa vida religiosas suportam o selo de uma autêntica abertura para o Espírito de Deus (Jacques DUPUIS, 1976, p. 206).

Com relação à pergunta se é possível à teologia cristã reconhecer a divina revelação em outros textos canônicos e outras tradições escriturais e em que isso implica para a doutrina da divina inspiração, Dupuis responde positivamente, reafirmando que "o Espírito alcança os homens [e mulheres] de outras fés através de canais viáveis para sua operação divina, nomeadamente as sagradas escrituras e as práticas sacramentais que juntos constituem sua tradição religiosa" (Jacques DUPUIS, 1976, p. 219).

Isso retoma a ideia das "sementes do Verbo" que estava presente nos Primeiros Padres da Igreja em sua tentativa de transmissão da mensagem cristã às outras tradições religiosas de seu tempo. Uma vez aplicando essa ideia à questão das escrituras, a pergunta que se segue é a respeito daquilo que faz de um livro sagrado uma escritura sagrada, ou colocado de outra forma, os textos reconhecidos como sagrados em outras tradições religiosas podem ser considerados escrituras sagradas em sentido teológico, uma vez que são consideradas como "sementes do Verbo"? (cf. Jacques DUPUIS, 1976, p. 219-227)

Para responder a essa pergunta, Dupuis chama a atenção para a diferenciação entre profetismo, revelação e Sagrada Escritura. Segundo ele, para a teologia cristã, Sagrada Escritura contém o registro da divina revelação, de maneira que Deus mesmo seja seu autor. Claramente, Dupuis não defende aqui certo transe naquele que escreve o texto. Quem escreve o texto tem todas as suas faculdades mentais e interpretativas, mas somente chama a atenção que, na Sagrada Escritura, há uma coautoria entre Deus e homem. 
Dupuis afirma que as experiências que os/as sábios/as de outras tradições religiosas tiveram é também uma experiência do Espírito e, assim, pode admitir que Deus tivesse querido falar com as outras nações através de seus/as profetas/profetisas. Dessa forma, Dupuis considera que as escrituras sagradas de outras tradições religiosas podem ser vontade do próprio Deus.

Dupuis, no entanto, não equipara essas sagradas escrituras com a revelação em Jesus Cristo. Em seu pensamento, claramente, nada pode ser adicionado à revelação definitiva que ocorre em Jesus Cristo.

Dessa forma,

"as sementes do Verbo" contidas naquelas escrituras [não cristãs] são palavras seminais de Deus nas quais a influência do seu Espírito está perdida. A influência do Espírito é universal e estende das palavras faladas por Deus à humanidade em todos os estágios de sua auto revelação para ela ${ }^{8}$ (Jacques DUPUIS, 1976, p. 227)

\section{UMA PROPOSTA TRINITÁRIA}

Em sua obra maior, intitulada Rumo a uma teologia cristã do pluralismo religioso, é possível perceber a tentativa de Jacques Dupuis em propor uma teologia do pluralismo religioso de caráter trinitário (cf. Manuel HURTADO, 2012, p. 115-147). Em suas palavras:

[...] nossa intenção é bem diferente: é mostrar que uma reivindicação bem ponderada da unicidade e universalidade de Jesus Cristo deixa o espaço para uma teologia "aberta" das religiões e do pluralismo religioso. Uma perspectiva cristológica trinitária permite reconhecer especialmente a presença e a atividade continuadas do Verbo de Deus e do Espírito de Deus (Jacques DUPUIS, 1999, p. 389).

Segundo seu pensamento, isso faz pensar que "a ação salvífica de Deus por meio Logos não encarnado (Lógos asarkos) persiste também

8 Digno de nota é o fato de que a relação entre a ação do Espírito e os textos sagrados das outras religiões também foi abordada por Dupuis em sua obra DUPUIS, Jesus-Christ a la reencontre des religions, p. 197-227, sem haver nenhuma consideração nova em relação àquilo que já estava proposto na obra que abordarmos anteriormente, o que também é apontado por Amos Yong em YONG, The turn to pneumatology in Christian theology of religions: conduit or detour?, p. 437-454. 
depois da encarnação do Logos, assim como existe a ação salvífica pela presença universal do Espírito, quer antes quer depois do evento histórico Jesus Cristo", de maneira que seria possível pensar outras figuras salvíficas que seriam iluminadas pelo Verbo ou inspiradas pelo Espírito de acordo com o plano de Deus para a humanidade (cf. Jacques DUPUIS, 1999, p. 413).

Ainda que afirme que o Verbo não pode ficar separado da carne por ele assumida, o autor considera que o Verbo e essa carne permanecem distintos um do outro, fazendo uma distinção entre a ação humana do Lógos ensarkos que é o "sacramento universal da ação salvadora de Deus” da ação do Logos. O Logos asarkos tem assim uma ação distinta daquela do Logos, ainda que não seja considerada por ele como uma economia da salvação distinta, mas "expressão da gratuidade superabundante e da liberdade absoluta de Deus" (Jacques DUPUIS, 1999, p. 413).

É com isso em mente que afirmará que "a perspectiva trinitára sobre a teologia do pluralismo religioso pediria observações análogas sobre a presença universal permanente do Espírito", de maneira que é possível ver que "o Espírito de Deus está universalmente presente e ativo, antes e depois do evento", havendo uma "relação de condicionamento recíproco" entre o Espírito e o evento-Cristo pelo qual o Espírito pode ser chamado como Espírito de Cristo (cf. Jacques DUPUIS, 1999, p. 415).

Por fim, Dupuis resgata a imagem das duas mãos do Pai proposta por Irineu:

A economia salvífica de Deus é uma só, da qual o evento-Cristo é ao mesmo tempo o ponto culminante e o sacramento universal; mas o Deus que salva é "três", onde cada um dos três é pessoalmente distinto e permanece ativo de maneira distinta. Deus salva com as “duas mãos" (Jacques DUPUIS, 1999, p. 415).

\section{CONCLUSÃO}

Começamos esta reflexão pela referência à visão do mundo antigo acerca de quais pessoas gozavam da dignidade de portar semelhança com o divino. A narrativa bíblica da criação registrada em Gênesis 1 será assertiva ao democratizar, a homens e mulheres, a despeito de sua 
classe social, econômica ou pertença étnica, o valor humano básico. Infelizmente, a história da fé do Antigo Israel, bem como da fé cristã, se deixou conduzir para longe dessa percepção. Abordamos apenas um dentre os vários recortes a que se poderia remeter para demonstrar a dificuldade básica de reconhecimento da igualdade entre os diversos seres humanos - muitos outros poderiam ser aludidos.

Um problema antropológico que pode ser verificado no âmbito interno e externo dos grupos religiosos, em especial aqueles que primam pela exclusividade do conteúdo que proclamam.O Cristianismo se posicionou diante de outras culturas, etnias e religiões com ares de superioridade e, portanto, uma vinculação a ser percebida de maneira normativa por todos que com ele tivessem contato. Mesmo teóricos/as que procuraram problematizar a relação do Cristianismo com outras tradições religiosas, por vezes caíram no erro de arrogar para si proeminência.

Diante do exposto, perguntamo-nos se não seria a tentativa de Dupuis de trabalhar o diálogo inter-religioso por meio da pneumatologia limitada e dentro de uma perspectiva inclusivista que segue pela linha de se ver superior às outras religiões, considerando-as apenas como estágios inferiores para a verdadeira religião que é encontrada no Cristianismo?A nosso ver, a resposta a essa pergunta é positiva e deve ser vista dentro de todo quadro de uma teologia eurocêntrica da qual Dupuis é integrante.

Sabemos que toda teologia é fruto de seu tempo e reflexo de uma história que lhe é anterior, de maneira que, para fazer uma teologia atual, é necessário olhar para o passado, para entender o presente, no intuito de caminhar rumo a novas teologias que façam sentido para homens e mulheres de nosso tempo.

A dinâmica da superioridade ainda se faz presente em diversos ambientes cristãos e perpassa também o próprio modo de fazer teologia, até mesmo em temas tidos como de fronteira, tal como o diálogo inter-religioso. Nesse sentido, é de grande valia os diversos trabalhos propostos pelas diversas teologias, dentre elas, as teologias feministas, que visam ressignificar abordagens já consolidadas pelo viés da superioridade, dentre outras, trazendo novos olhares e críticas ao modo atual de se fazer teologia nos diversos círculos cristãos. 


\section{REFERÊNCIAS}

CONSTITUIÇÃO PASTORAL GAUDIUM ET SPES. Documentos do Concílio Vaticano II. Disponível em: <http://www.vatican.va/archive/hist_councils/ii_vatican_council/documents/ vat-ii_const_19651207_gaudium-et-spes_po.html>. Acesso em 22.02.2019.

DELUMEAU, Jean. História do medo no Ocidente. 1300-1800. São Paulo: Companhia das Letras, 1989.

DUPUIS, Jacques. Jesus-Christ a la reencontre des religions. Paris: Desclé, 1989.

DUPUIS, Jacques. Jesus Christ and His Spirit. Nova Delhi: Theological Publicatinos in India, 1976.

DUPUIS, Jacques. Rumo a uma teologia cristã do pluralismo religioso. São Paulo: Paulinas, 1999.

HARRIS, R.Laird; ARCHER JR, Gleason L.; WALTKE, Bruce K. Dicionário Internacional de Teologia do Antigo Testamento. São Paulo: Vida Nova, 1998.

LOUTH, Andrew. (Ed) Genesis 1-11. Ancient Christian Commentary on Scripture. Old Testament. Illinois: Inter Varsity Press, 2001.

SKA, Jean-Louis. O canteiro do Pentateuco. Problemas de composição e de interpretação, aspectos literários e teológicos. São Paulo: Paulinas, 2016.

STEGEMANN, Ekkehard W.; STEGEMANN, Wolfgang. História social do protocristianismo: Os primórdios no judaísmo e as comunidades de Cristo no mundo mediterrâneo. São Paulo: Paulus, São Leopoldo: Sinodal, 2004.

STRÖHER, Marga J. Corpos, poderes e saberes nas primeiras comunidades cristãsUmaaproximação a partir das “Cartas Pastorais". In: STRÖHER, Marga J.; DEIFELT, Wanda;MUSSKOPF, André. (Orgs.) À flor da pele: Ensaios sobre gênero e corporeidade. SãoLeopoldo: Editora Sinodal, 2004, p. 105-136.

YONG. Amos. The Turn to Pneumatology in Christian Theology of Religions: Conduit or Detour?. Journal of Ecumenical Studies, Philadelphia, v. 35, n. 3-4, p. 437-454, Summer/ Fall, 1998.

Submetido em: 4-4-2019

Aceito em: 17-5-2019

Mandrágora, v.25, n. 1, 2019, p. 33-49 